\title{
Target Cell Subpopulations for Human Thymic Epithelial Conditioned Medium in the Mouse Thymus
}

\author{
ROBERT OOSTEROM ${ }^{1}$ AND LOUIS KATER
}

\begin{abstract}
Division of Immunopathology, Departments of Internal Medicine and Pathology, University
\end{abstract} Hospital, Utrecht, The Netherlands

Received November 29, 1979

\begin{abstract}
Human thymic epithelial conditioned medium (HTECM) increases the reactivity of human and mouse thymocytes to Con $\mathrm{A}$ and PHA, and the reactivity of mouse thymocytes in mixed lymphocyte culture and in in vivo graft versus host reaction. In this study target cells for HTECM in subpopulations of mouse thymocytes at various times after hydrocortisone $(\mathrm{HC}$ ) treatment were investigated. The PHA but not the Con A response of cortisone-resistant thymocytes $\left(\mathrm{T}_{\mathrm{cr}}\right.$, Day 3 after $\mathrm{HC}$ ) was augmented by HTECM. Twelve days after HC treatment the thymus contained a population of cells $\left(\mathrm{T}_{12}\right)$ unresponsive to Con A and PHA and unresponsive to HTECM. This situation remained until Day 17. Between Days 17 and 19 the mitogen response was still very low but HTECM induced a marked increase in mitogen reactivity. After Day 19 the responses gradually returned to normal values. Histologically 12 days after $\mathrm{HC}$ the thymus corticomedullary differentiation was completely effaced and it contained an almost homogenous population of immature lymphoid cells. Histology returned to normal 17 days after $\mathrm{HC}$. In the presence of $T_{\text {cr }}$ or lymph node (LN) cells, $T_{12}$ could be stimulated by mitogens. This response of mixtures of $T_{12}$ and $T_{c r}$ or $L N$ cells to mitogen was increased by HTECM. The addition of mitomycin-treated $T_{c r}$ also resulted in an increase in the mitogen reactivity of $T_{12}$ by HTECM. From these data we conclude that $T_{12}$, although very immature, are sensitive to HTECM but regulatory $T$ cells are needed to show this effect as measured by thymidine incorporation.
\end{abstract}

\section{INTRODUCTION}

The thymus of mice contains at least two populations of lymphoid cells which differ not only in localization (respectively, thymus cortex and medulla) but also in sensitivity to corticosteroids, antigenic properties of cell membrane, and immunocompetence (1). The ontogenetic relationship of the cortical and medullary thymocytes has been differently interpreted $(1,2)$. Humoral factors generated within the thymus can modulate the expression of differentiation antigens and immunocompetence of thymocytes (3), but little is known about the effects of thymic humoral factors on thymocyte subpopulations. We have recently shown that conditioned medium from human thymic epithelial cultures (HTECM) can increase the reactivity of human and mouse thymocytes to concanavalin A (Con A) and phytohemagglutinin (PHA) (4) and the reactivity of mouse thymocytes to

\footnotetext{
${ }^{1}$ Send requests for reprints to Robert Oosterom, Ph.D., Division of Immunopathology, University Hospital, Catharijnesingel 101, 3511 GV Utrecht, The Netherlands.
} 
allogeneic cells in the mixed lymphocyte reaction and graft versus host reaction (5). Using cortisone-resistant mouse thymocytes $\left(\mathrm{T}_{\mathrm{cr}}\right)$ obtained 3 days after hydrocortisone (HC) treatment, HTECM increased only the PHA response. Twelve days after $\mathrm{HC}$ no effect on either the Con A or the PHA response of thymocytes could be demonstrated (4).

In the present study the effect of HTECM on thymocyte subpopulations present in the thymus at varying times after $\mathrm{HC}$ treatment is further investigated and the results are correlated with the histology of the thymus.

\section{MATERIALS AND METHODS}

Human thymic epithelial cultures and control cultures. Thymic epithelial cells were cultured from human thymuses, obtained from children undergoing cardiac surgery. The cells were cultured in Hepes-buffered RPMI-1640 (H-RPMI) with 2 $\mathrm{m} M$ L-glutamine, penicillin (100 U/ml), streptomycin $(100 \mu \mathrm{g} / \mathrm{ml})$, and $20 \%$ heatinactivated human $\mathrm{AB}$ serum. Culture conditions and collection of conditioned media were described in detail elsewhere (4). Control cultures used were fibroblasts grown from a human cervical biopsy, epithelial cells grown from labial mucosae, obtained from patients undergoing labial biopsy, and amnion epithelial cells.

Mice. Female Swiss inbred mice were used. They were 6 to 8 weeks old at the start of the experiments.

Hydrocortisone treatment. Mice were injected i.p. with $2.5 \mathrm{mg}$ of hydrocortisone acetate (HC) (Hydro-Adreson, Organon, NL) at different times prior to the experiment. The animals were killed on the same day and thymus cells of three to six mice in each group were pooled.

Mitogen stimulation of mouse lymphocytes. Mice were killed by cervical dislocation. Thymuses and lymph nodes were dissected free of adjacent tissue under sterile conditions. The organs were minced in H-RPMI with antibiotics. Aggregates were removed by filtration through nylon wool and the cells were suspended in H-RPMI with bicarbonate, glutamine, antibiotics, and $10 \% \mathrm{AB}$ serum. Culture methods for mitogen stimulation and measurement of thymidine incorporation were as described before (4). Mitogen concentrations giving optimal stimulation of thymocytes from untreated mice were: Con A (Miles, Slough, U.K.), $2 \mu \mathrm{g} /$ culture; and PHA (Welcome, Beckenham, U.K.), $16 \mu \mathrm{g} /$ culture. The conditioned media were present during the entire culture period at a dilution of $1: 18$, previously shown to give optimal effects of HTECM on the mitogen response of mouse thymocytes (4). The results obtained with the different control conditioned media were comparable to each other and also to the baseline mitogen response obtained with plain culture medium. Therefore, the results with control conditioned media were left out of the figures. Results are expressed as the mean cpm of quadruplicate cultures \pm standard error (SE).

Mitomycin treatment of cells. Approximately $10 \times 10^{6}$ thymocytes obtained from mice 3 days after $\mathrm{HC}$ treatment were incubated at $37^{\circ} \mathrm{C}$ for $30 \mathrm{~min}$ in $1 \mathrm{ml}$ of RPMI containing $25 \mu \mathrm{g}$ of mitomycin C (Christiaens, Brussels, Belgium). The cells were washed three times and the number of viable cells was determined. 
Spontaneous uptake of tritiated thymidine. $\left[{ }^{3} \mathrm{H}\right] \mathrm{TdR}$ uptake was determined as an index of spontaneous proliferation of thymocytes. Thymocytes were isolated as described previously and $2 \times 10^{5}$ cells in $0.15 \mathrm{ml}$ of culture medium were labeled immediately with $1 \mu \mathrm{Ci}\left[{ }^{3} \mathrm{H}\right] \mathrm{TdR}(5 \mathrm{Ci} / \mathrm{mmol})$. Four hours later the cells were harvested, and radioactivity was measured as described previously.

Histological techniques. Thymic tissue was fixed in 75\% ethanol absolute with $20 \%$ formol and $5 \%$ acetic and embedded in paraffin wax. Six-micrometer-thick sections were stained with hematoxylin and eosin by standard histological technique. Additionally, thymus tissue of mice 12 days after $\mathrm{HC}$ treatment was embedded in methylmethacrylate, and 3- $\mu$ m-thick sections were cut on a Zeiss heavy-duty microtome and stained with Giemsa modified for plastic sections (6).

Fractionation of thymocytes. Thymocytes were separated on a bovine serum albumin (BSA) gradient as described (7). In brief, thymocytes were centrifuged and the cell pellet, containing maximal $2 \times 10^{8}$ cells, was resuspended in $1 \mathrm{ml}$ chilled 35\% BSA (Path-o-cyte 5, Miles Laboratories, Kankakee, Ill.). The cells were delivered into 5-ml Beckman nitrocellulose acetate tubes (sterilized by ethylene oxide). Over this layer was successively pipetted $1 \mathrm{ml}$ each of chilled 29 , 27,23 , and 10\% BSA in H-RPMI. The refractive index was used to determine the exact concentration of BSA. The gradients were centrifuged in a SW 50.1 rotor at $13,500 \mathrm{rpm}$ in a Beckman L3-50 ultracentrifuge at $4^{\circ} \mathrm{C}$ for $30 \mathrm{~min}$. Individual bands of cells were aspirated from each gradient and combined with the corresponding bands from other tubes. The top layer, between 10 and $23 \% \mathrm{BSA}$, is the A layer; between 23 and $27 \%$, the B layer; between 27 and $29 \%$, the C layer; and between 29 and $35 \%$, the D layer. Then the cells were washed, counted, and used in the mitogen stimulation assay.

Using the preceding method, Konda et al. (8) found that the upper layers contained the minor, low-density, cortisone-resistant subpopulation of thymocytes.

\section{RESULTS}

Effect of HTECM on the mitogen response of thymocytes at varying times after cortisone treatment. Increased reactivity to both Con A and PHA was seen in the first 5 days after $\mathrm{HC}$ treatment, when the total thymic cell number diminished (4). Histology revealed a thymocyte depletion of the cortex and a normal medulla (Fig. 1). During the subsequent regeneration of the thymus, the reactivity to both mitogens decreased and reached a minimum below Day 0 values around Day 12. The effect of HTECM on $\left[{ }^{3} \mathrm{H}\right] \mathrm{TdR}$ incorporation in Con A-stimulated thymocytes was absent at Days 3-5, reached normal levels at Day 7, and was absent again around Day 12. The increase in $\left[{ }^{3} \mathrm{H}\right] \mathrm{TdR}$ incorporation in PHA-stimulated thymocytes caused by HTECM was maximal at Days 3-5 and dropped to zero around Day 12 (4). The number of thymocytes in the thymus 12 days after HC treatment was about $60 \%$ of that in the normal thymus. Histologically at Day 12 the thymus corticomedullary differentiation was completely effaced and it contained an almost homogeneous population of immature lymphoid cells with nucleoli and many mitoses (Fig. 2). The in vitro spontaneous $\left[{ }^{3} \mathrm{H}\right] \mathrm{TdR}$ incorporation dropped at Day 3 , increased during regeneration of the thymus, until a maximum at Day 12, and 
was still higher than in untreated mice when measured at Day 38, whereafter it returned to normal values (Fig. 3). The peak at Day 12 corresponded with the high mitotic activity seen in the tissue sections.

The response to Con A and PHA remained very low from Day 12 until Day 17 (Figs. 4a and b). After Day 17 the response increased gradually, reaching normal values at Day 24, and was higher than in untreated mice at Day 38; thereafter the response returned to normal values. Target cells for HTECM were virtually absent in thymuses from mice at Days 12 to 17 after HC treatment. At Day 17 the mitogen response was still low but a clear effect of HTECM was noted. The histological picture of the thymus was normal again from this day on.

Comparison of thymocytes from untreated mice and from mice 12 days after $H C\left(T_{12}\right)$. To study the presence of target cells for HTECM in a $T_{12}$ population, we first compared the proliferative response to Con A and PHA of thymocytes from untreated mice and $T_{12}$. Mitogen dose-response curves for thymocytes from untreated mice and $T_{12}$ are given in Fig. 5. Maximal responses for both cell populations were obtained at $2 \mu \mathrm{g}$ Con A and $16 \mu \mathrm{g}$ of PHA. The effect of HTECM on cell dose-response curves for these two cell populations, using optimal mitogen concentrations, is shown in Fig. 6. The Con A and PHA response of $T_{12}$ was much lower than the response of thymocytes from untreated mice at all cell concentrations tested. The effect of HTECM on the Con A response of $\mathrm{T}_{12}$ was very low when a density of 1 or $2 \times 10^{5}$ cells per culture was used, but a clear effect was seen at higher cell concentrations. The effect of HTECM on the PHA response of $T_{12}$ remained very low at all cell concentrations.

To study the composition of cells in the thymus, we separated thymocytes from untreated mice and mice treated 12 days earlier with $\mathrm{HC}$ by equilibrium density centrifugation in a discontinuous BSA gradient. The distributions of the two cell populations did not differ markedly. The lower response of $\mathrm{T}_{12}$ was associated with a lower response of cells from layers $A$ and $B$ (Table 1).

Target cells for HTECM in $T_{12}$ population. It is known that immature lymphocytes can respond to Con $A$ in the presence of Con A-stimulated mature $T$ lymphocytes $(9,10)$. Therefore, we tested the effect of HTECM on the T-mitogen response of mixtures either of $T_{12}$ and $T_{c r}$ or of $T_{12}$ and lymph node ( $L N$ ) cells. In these experiments the total cell number was kept constant. As described earlier (4) the Con $A$ and PHA response increased with increasing percentages of $T_{c r}$. The effect of HTECM on the Con $A$ response was already seen with $5 \% \mathrm{~T}_{\mathrm{cr}}$ and reached its maximum with $20 \% \mathrm{~T}_{\text {er }}$. No effect was seen with either $100 \% \mathrm{~T}_{\text {cr }}$ or $100 \% \mathrm{~T}_{12}$. The effect of HTECM on the PHA response increased with rising percentages of $\mathrm{T}_{\mathrm{cr}}$ and was maximal with $100 \% \mathrm{~T}_{\mathrm{cr}}$. The corresponding experiment was done, using $\mathrm{LN}$ cells instead of $\mathrm{T}_{\mathrm{cr}}$. This resulted in a maximum effect of HTECM for both mitogens with $50 \%$ LN cells. No effect was seen with LN cells alone (Fig. 7).

To investigate whether the effect of HTECM on mixtures of $T_{12}$ and $T_{c r}$ had to be attributed to an effect on $T_{12}$, the following experiment was done. A constant number of $T_{12}$ was mixed with different numbers of mitomycin-treated $T_{c r}$. As shown in Fig. 8, mitogen responses of $T_{12}$ increased with higher numbers of mitomycin-treated $T_{c r}$. The effect of HTECM, being very low on $T_{12}$ alone, be- 


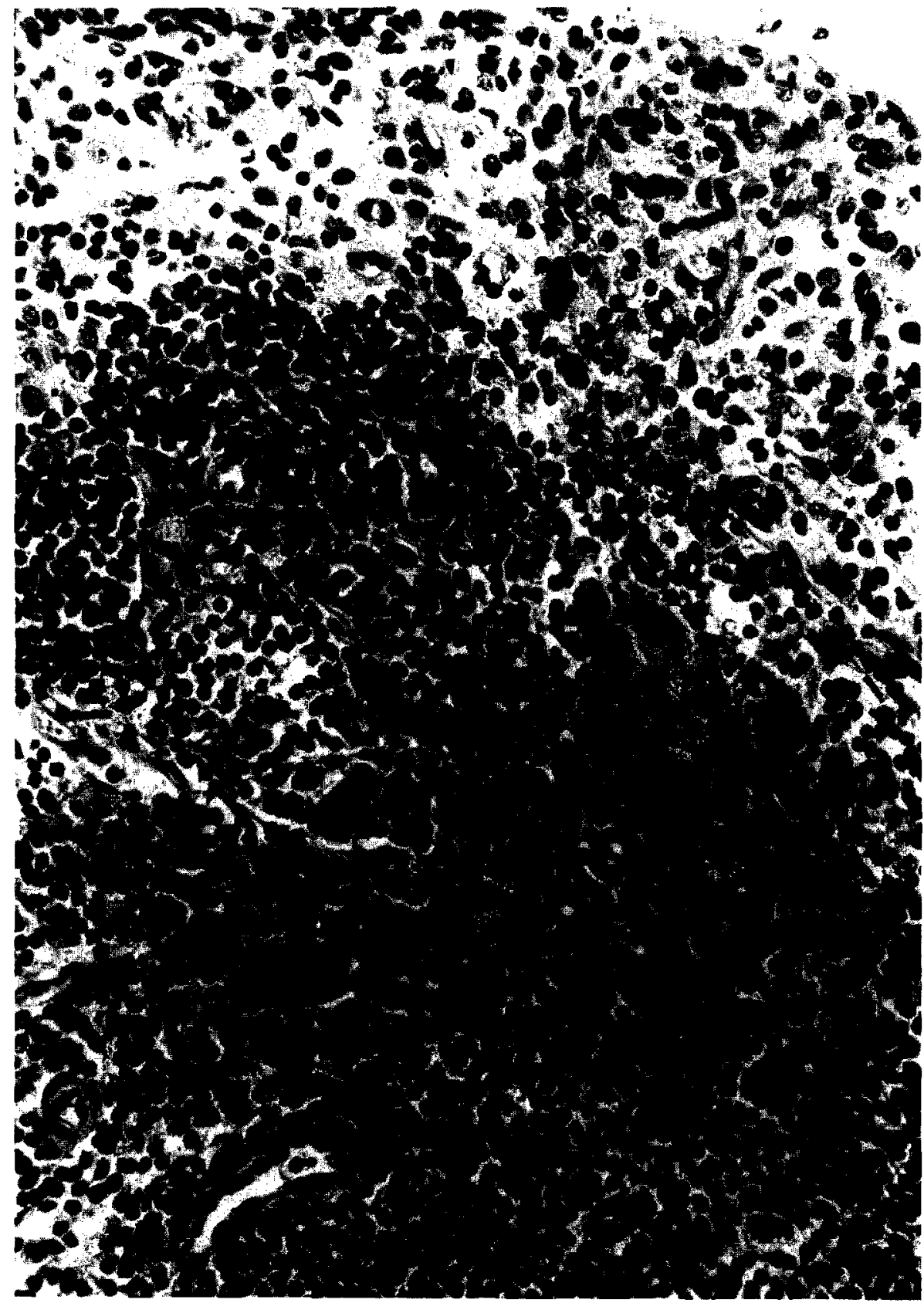

FIG. 1. Thymus of Swiss mouse 3 days after $\mathrm{HC}$ treatment. $\mathrm{H} \& \mathrm{E}, \times 250$.

came more distinct when mitomycin-treated $T_{\mathrm{cr}}$ were added. Maximum values were obtained from $4 \times 10^{4}$ mitomycin-treated $\mathrm{T}_{\mathrm{cr}}$ onward. This is about $20 \%$ of the total cell number, which is comparable with the results described previously. 


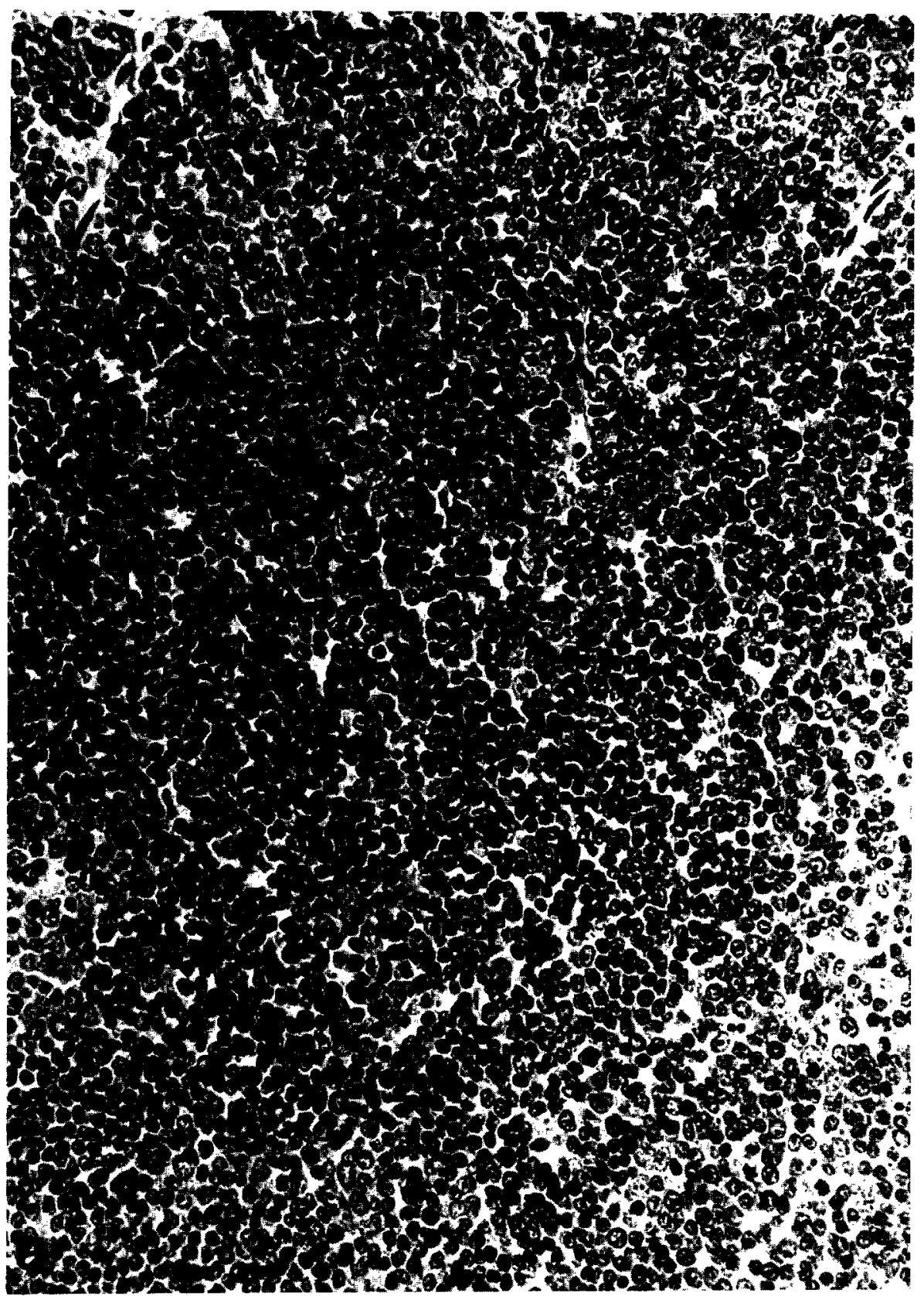

Fig. 2. Thymus of a mouse 12 days after HC treatment. (a) Corticomedullary differentiation is effaced. H\&E, $\times 250$. (b) Mainly blast-like cells with prominent nucleoli, many mitoses are seen. Giemsa, $\times 630$.

\section{DISCUSSION}

Several thymic humoral factors influencing T-lymphocyte maturation have been described (3). The generally accepted target cell for thymic factors is the post- 


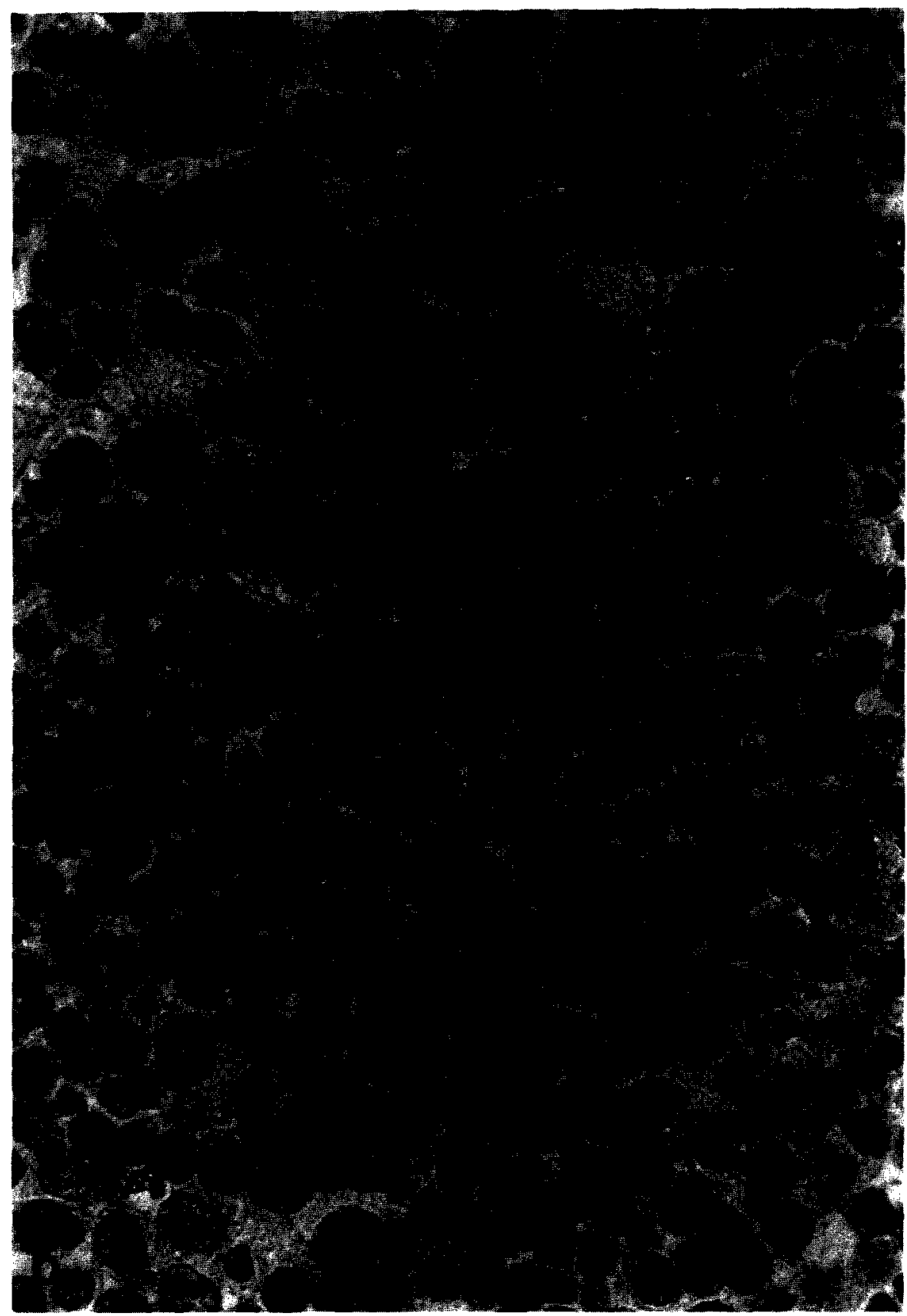

FIG. 2-Continued

thymic precursor $\mathrm{T}$ cell generated from a prethymic cell under the direct influence of the thymic epithelial microenvironment $(3,11)$. In earlier studies we have demonstrated that human thymic epithelial conditioned medium (HTECM) increased the Con A and PHA reactivity of human and mouse thymocytes (4) and 


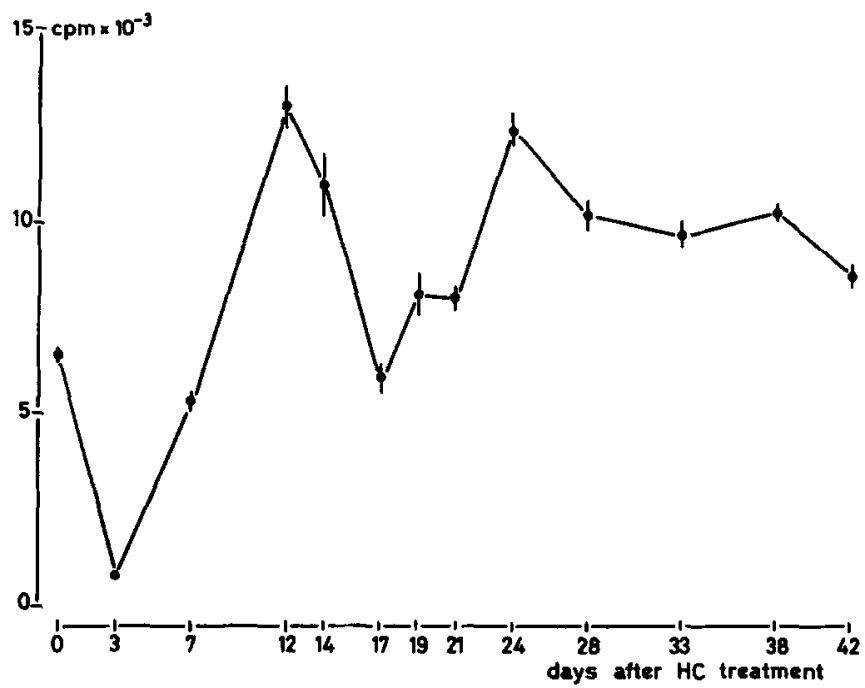

FIG. 3. Spontaneous thymidine incorporation into thymocytes from mice at various times after $\mathrm{HC}$ treatment. $\left[{ }^{3} \mathrm{H}\right] \mathrm{TdR}$ uptake during the first $4 \mathrm{hr}$ of culture.

also the MLC and graft versus host reactivity of mouse thymocytes (5). Target cells for HTECM have been found in cortisone-sensitive and, to a lesser extent, in cortisone-resistant thymocyte subpopulations (4).

Twelve days after $\mathrm{HC}$ injection the thymus lymphoid population consists mainly of immature cells. Histologically most of these cells resemble blast-like lymphocytes, while numerous mitoses are seen. Immunocompetence of thymocytes is almost completely confined to the cortisone-resistant population. The low response of $T_{12}$ to mitogen is therefore likely to be due to a change in the pool of $\mathrm{T}_{\mathrm{cr}}$. Possible explanations are as follows.

(1) Repopulating cells may suppress the response of $T_{c r}$. However, data of Jacobsson and Blomgren (9), on a synergistic effect of mixtures of thymocytes 14 days after $\mathrm{HC}$ with $\mathrm{T}_{\mathrm{er}}$ or $\mathrm{LN}$ cells, are against this possibility.
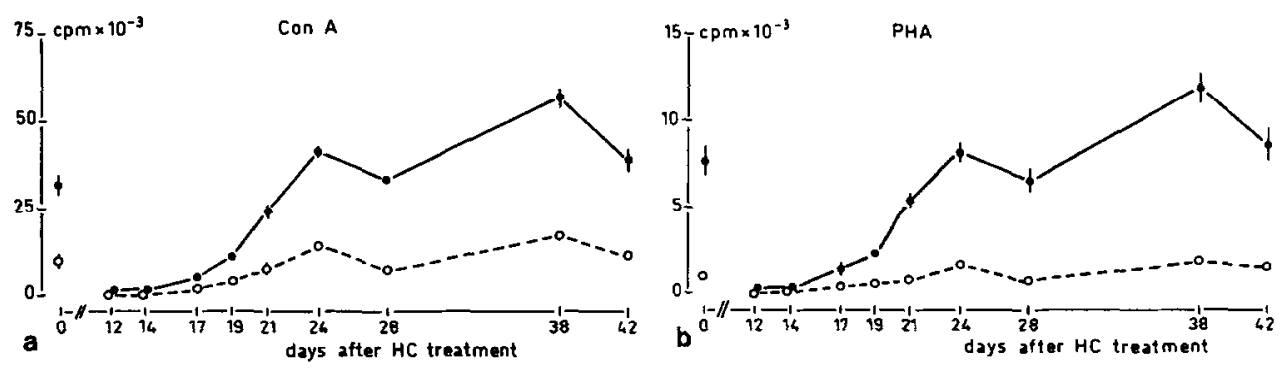

FIG. 4. $\left[{ }^{3} \mathrm{H}\right] \mathrm{TdR}$ incorporation into Con A (a)- and PHA (b)-stimulated thymocytes from mice 12 to 42 days after HC treatment, cultured with HTECM (_) or plain medium (---). 


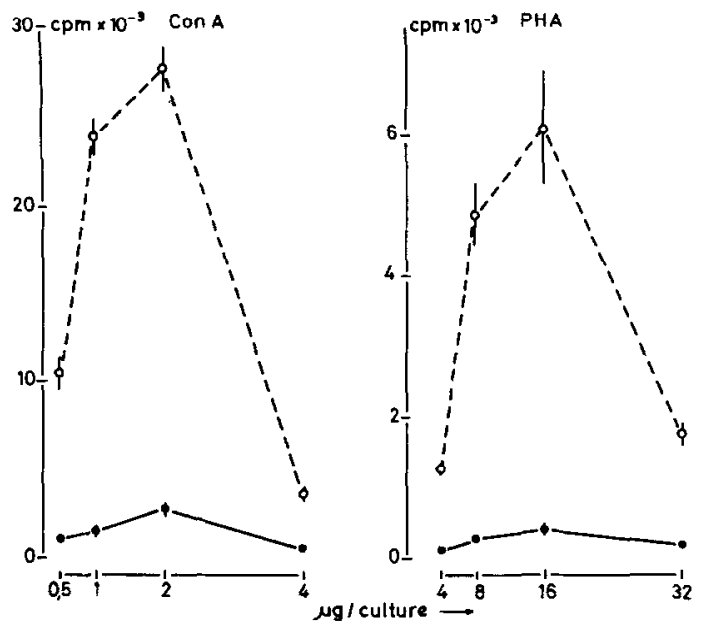

FIG. 5. $\left[{ }^{3} \mathrm{H}\right] \mathrm{TdR}$ incorporation into thymocytes from untreated mice (--) and $\mathrm{T}_{12}(-)$ stimulated with different concentrations of mitogen.

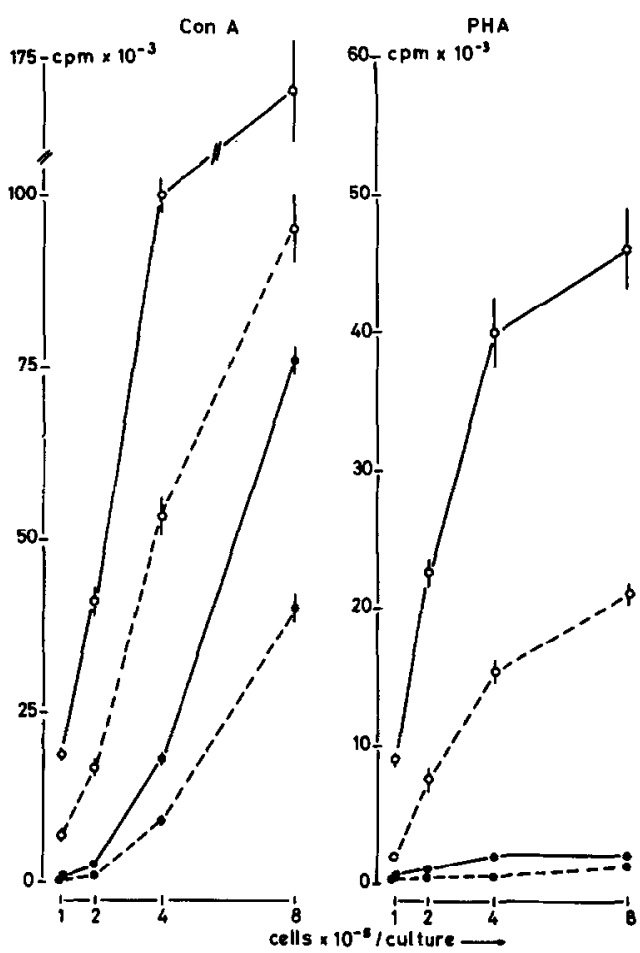

Fig. 6. Cell dose-response curves for mitogen-stimulated thymocytes expressed as $\left[{ }^{3} \mathrm{H}\right] \mathrm{TdR}$ incorporation. Thymocytes from untreated mice cultured with HTECM $\left(\mathrm{O}_{-} \mathrm{O}\right)$ or plain medium $(\mathrm{O}-\mathrm{-}-\mathrm{O})$ and $T_{12}$ cultured with HTECM (-๑) or plain medium (---). In routine assays, $2 \times 10^{5}$ cells $/$ culture were used. 
TABLE 1

Thymocyte Subpopulations from BSA Gradients"

\begin{tabular}{lcccc}
\hline & \multicolumn{4}{c}{ Cell layer } \\
\cline { 2 - 5 } & $\mathrm{A}$ & $\mathrm{B}$ & $\mathrm{C}$ & $\mathrm{D}$ \\
\hline Thymocytes from & & & \\
$\quad$ untreated mice & 9.7 & 22.1 & 32.6 & 35.6 \\
$\quad$ Relative distribution (\%) & 120,825 & 50,200 & 65 & 80 \\
$\quad$ Response to Con A (cpm) & 27,565 & 9,590 & 5 & 0 \\
$\quad$ Response to PHA (cpm) & & & & \\
Thymocytes from mice & 4.0 & 19.6 & 34.9 & 41.5 \\
12 days after HC treatment & 16,210 & 1,410 & 200 & 455 \\
$\quad$ Relative distribution (\%) & 2,280 & 170 & 30 & 235 \\
$\quad$ Response to Con A (cpm) & & & \\
$\quad$ Response to PHA (cpm) & & & & \\
\hline
\end{tabular}

a Thymocytes from untreated mice and from mice treated 12 days earlier with hydrocortisone were separated by equilibrium density centrifugation in a discontinuous BSA gradient (see Materials and Methods).

${ }^{b}$ Mitogen response of $2 \times 10^{5}$ cells/culture was measured; background cpm are subtracted. Results representative of three separate experiments are shown.

(2) A change in the physical properties of $\mathrm{T}_{\mathrm{er}} \mathbf{1 2}$ days after $\mathrm{HC}$ has been suggested $(12,13)$, resulting in a loss of capacity to respond to mitogen.

(3) Cortisone-resistant thymocytes may have been diluted by the repopulating (immature) cells. Since the cell number at Day 12 is about $60 \%$ of that in the normal thymus, we are dealing not merely with a numerical dilution, but also with a decrease in absolute numbers of $\mathrm{T}_{\mathrm{rr}}$. Data on electrophoretic mobility of thymocytes various days after $\mathrm{HC}$ treatment are also indicative of a depletion of $T_{\mathrm{cr}}$ at Day 12 (12). Our experiments with fractionated thymocytes demonstrate (a) a
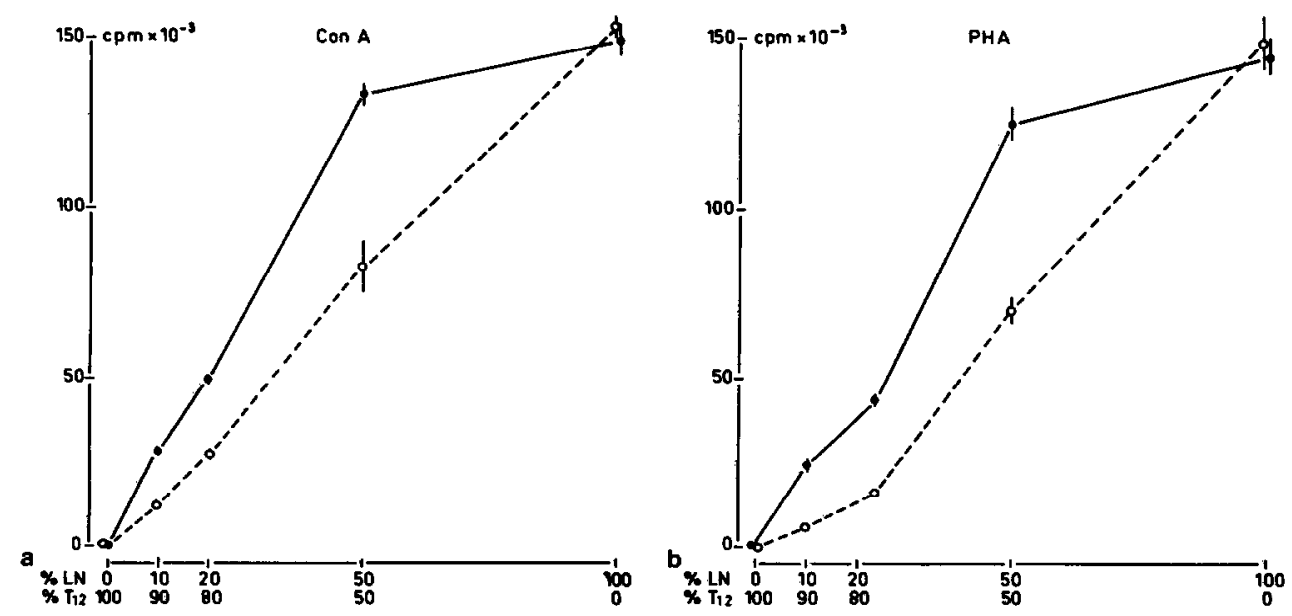

FIG. 7. Effect of HTECM (- - ) and plain medium (---) on $\left[{ }^{3} \mathrm{H}\right] \mathrm{TdR}$ incorporation into mixtures of $T_{12}$ and LN cells stimulated with Con A (a) or PHA (b). The total number of cells cultured per well was kept at $2 \times 10^{5}$. 


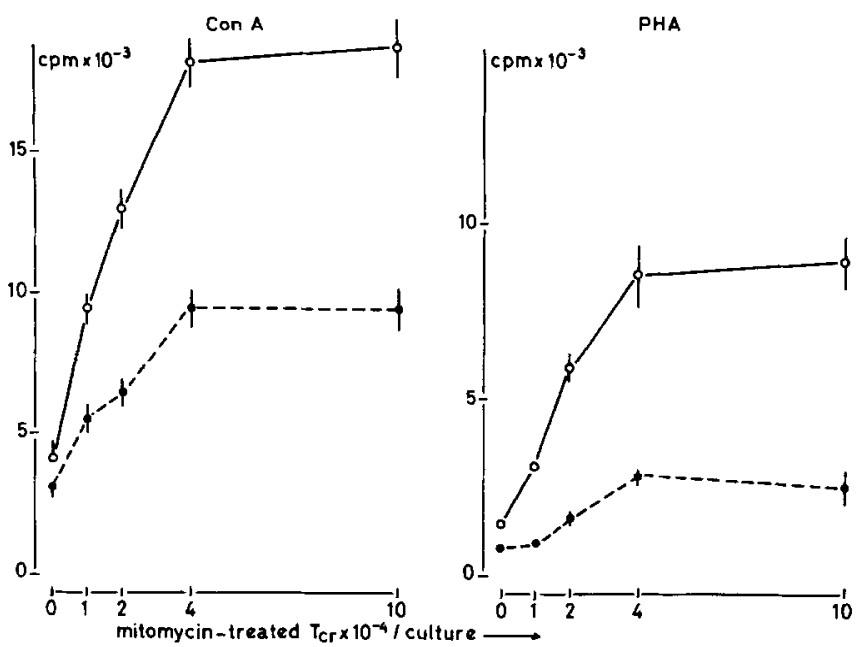

FIG. 8. Effect of HTECM (-) and plain medium (- $(-)$ on $\left[{ }^{3} \mathrm{H}\right] \mathrm{TdR}$ incorporation into mitogenstimulated thymocytes. Each well contained $2 \times 10^{5} \mathrm{~T}_{12}$, to which different numbers of mitomycintreated $T_{c r}$ were added. The cpm of mitomycin-treated $T_{c r}$ cultured alone were subtracted.

similar distribution for $T_{12}$ and thymocytes from untreated mice and (b) a decrease in the response of $T_{12}$ cells in layers $A$ and $B$. Thus, in the $T_{12}$ population many fewer (mature) cells able to respond to Con A and PHA are present. The distribution of the immature blast-like lymphoid cells in $\mathrm{T}_{12}$ showing a high spontaneous proliferation (Fig. 3) is unknown. It has been reported that proliferating cells in the regenerating mouse thymus are not confined to a certain layer in BSA density gradients (14). $T_{\mathrm{cr}}$ normally sediment in layers $A$ and $B$, and are depleted in the thymus 12 days after $\mathrm{HC}$ treatment.

(4) There may have been an intrathymic death of $\mathrm{T}_{\mathrm{er}} 12$ days after $\mathrm{HC}$ treatment or $\mathrm{T}_{\mathrm{cr}}$ may have migrated to peripheral lymphoid organs. Data from studies indicating the presence of lymph and blood vessels originating in the medulla and leaving the thymus $(15,16)$ favor the concept of emigration of $T_{\mathrm{cr}}$. On the other hand, several reports stress that an important fraction of $\mathrm{T}_{\mathrm{cr}}$ is resident in the thymus and is not capable of populating peripheral lymphoid organs $(11,17)$. The data on the very low response of $\mathrm{T}_{12}$ to mitogens found in our experiments and those of others (9) and the lower response of the low-density thymocytes are suggestive of emigration of (a fraction of) $T_{c r}$ from the thymus, at least under the given experimental conditions.

Between Days 12 and 17 after HC treatment, apparently a shift in cell composition occurs, resulting in the reappearance of a cell population directly sensitive to HTECM and mitogens. With regard to the ontogenetic pathway of thymocytes, our experiments indicate that the immature thymocyte population appears in the mouse thymus before the more mature medullary thymocyte population 12 to 17 days after $\mathrm{HC}$ treatment. This may correlate with the findings of Weissman (18, 19) that in situ labeled outer cortical large thymocytes developed into medullary $T_{c r}$. Our data do not exclude that $T_{c s}$ and $T_{c r}$ represent separate lines of differentiation, as has been suggested by Shortman and Jackson (20). However, the fact 
that, under appropriate conditions, $T_{12}$ can be induced to react to mitogen provides evidence against the possibility that immature cortical thymocytes represent a sterile differentiation pathway.

Thymocytes, 12 days after HC treatment, as such are almost unresponsive to mitogen and HTECM. But when cultured with mitogen under conditions allowing proliferation, i.e., with $T_{c r}$ or $L N$ cells, a clear effect of HTECM on the mitogen response of $T_{12}$ was observed (4) (Fig. 7). Using mixtures of $T_{12}$ and $T_{c r}$, the effect of HTECM on the PHA response of $T_{12}$ could be attributed to the relative number of $T_{c r}$. It can be argued that any effect on $T_{12}$ is masked by the effect on the response of $T_{c r}$. But it is obvious that HTECM augments both the Con A and PHA response of $T_{12}$ in the presence of $L N$ cells, since the mitogen response of $L N$ cells alone is not affected by HTECM.

Mitomycin treatment of $T_{c r}$ does not abolish their capacity to enhance thymidine incorporation in $T_{12}(9)$. The addition of mitomycin-treated $T_{c r}$ results in an increased mitogen responsiveness of $\mathrm{T}_{12}$ and a marked effect of HTECM is seen.

Probably mature $T$ cells exert their effect by soluble factors $(10,21-23)$. One of these, i.e., T-cell growth factor (TCGF; 24) is not present in HTECM (K. A. Smith and $R$. Oosterom, unpublished observation). The mechanism may be that in the presence of HTECM, more $\mathrm{T}_{12}$ cells are activated following mitogen stimulation; these cells are then prompted to proliferation by T-cell products like TCGF.

These observations therefore suggest that it is unlikely that the unresponsiveness of $T_{12}$ to mitogen is solely due to the immaturity of the $T$-cell population. On the contrary, we believe that $T_{c r}$ and $L N$ cells function as regulatory cells which are needed to allow for expression of the effect of HTECM on immature T lymphocytes.

\section{ACKNOWLEDGMENTS}

The authors are very much indebted to Mr. J. G. N., Geertzema for technical assistance, Mr. J. Hof for preparing plastic sections, and Mrs. J. v. d. Avert for secretarial work. We wish to thank Prof. Dr. J. A. M. van Unnik for examining the tissue sections and Dr. J. Huber for criticizing the manuscript.

\section{REFERENCES}

1. Cantor, H., and Weissman, I., Progr. Allergy 20, 1, 1976.

2. Shortman, K., Von Boehmer, H., Lipp, J., and Hopper, K., Transplant. Rev. 25, 163, 1975.

3. Bach, J. F., and Carnaud, C., Progr. Allergy 21, 342, 1976.

4. Oosterom, R., Kater, L., and Oosterom, J., Clin. Immunol. Immunopathol. 12, 460, 1979.

5. Oosterom, R., and Kater, L., Ann. N.Y. Acad. Sci. 332, 113, 1979.

6. Te Velde, J., Burkhardt, R., Kleiverda, K., Leenheers-Binnendijk, L., and Sommerfeld, W., Histopathology 1, 319, 1977.

7. Konda, S., Stockert, E., and Smith, R. T., Cell. Immunol. 7, 275, 1973.

8. Konda, S., Nakao, Y., and Smith, R. T., J. Exp. Med. 136, 1461, 1972.

9. Jacobsson, H., and Blomgren, H., Cell. Immunol. 11, 427, 1974.

10. Paetkau, V., Mills, G., Gerhart, S., and Monticone, V., J. Immunol. 117, 1320, 1976.

11. Stutman, O., In "Contemporary 'lopics in Immunobiology" (O. Stutman, Ed.), Vol. 7, p. 1, Plenum Press, New York, 1977.

12. Dumont, F., J. Immunol. 34, 841, 1978.

13. Jacobsson, H., and Blomgren, H., Cell. Immunol. 4, 93, 1972.

14. Boersma, W., Betel, I., and Van der Westen, G., Eur. J. Immunol. 9, 45, 1979.

15. Baak, J. P. A., and Kater, L., Proc. Kon. Nederl. Akad. Wet. Ser. C 78, 123, 1975. 
16. Baak, J. P. A., Meyer, C. J. L. M., Nieuwenhuyzen Kruzeman, A. C., Langevoort, H. L., and Kater, L., J. Immunol. 117, 463, 1976.

17. Elliot, E. V., Nature New Biol. 242, 150, 1973.

18. Weissman I. L., J. Exp. Med. 137, 504, 1973.

19. Weissman, I. L., Small, M., Fathman, C. G., and Herzenberg, L. A., Fed. Proc. 34, 141, 1975.

20. Shortman, K., and Jackson, H., Cell. Immunol. 12, 230, 1974.

21. Jacobsson, H., and Blomgren, H., Scand. J. Immunol. 4, 791, 1975.

22. Gillis, S., Union, N. A., Baker, P. E., and Smith, K. A., J. Exp. Med. 149, 1460, 1979.

23. Smith, K. A., Gillis, S., Baker, P. E., McKenzie, D., and Ruscetti, F. W., Ann. N.Y. Acad. Sci. 332, 423, 1979.

24. Gillis, S., Ferm, M. M., Ou, W., and Smith, K. A., J. Immunol. 120, 2027, 1978. 